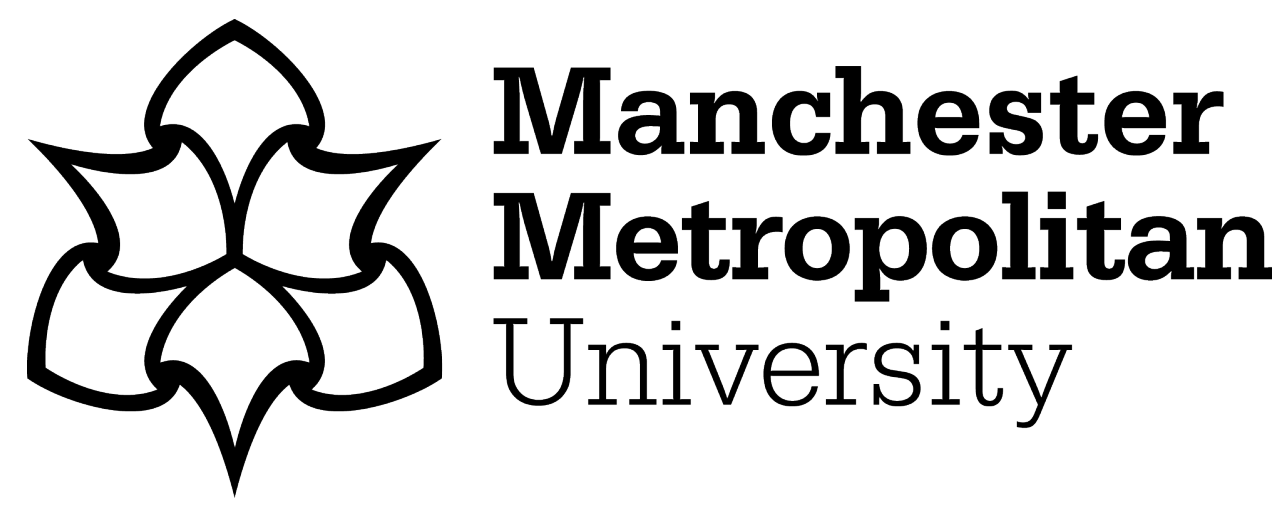

Pringle, A, Parnell, D, Zwolinsky, S, Hargreaves, J and McKenna, J (2014) Effect of a health-improvement pilot programme for older adults delivered by a professional football club: the Burton Albion case study. Soccer and Society, 15 (6). pp. 902-918. ISSN 1466-0970

Downloaded from: https://e-space.mmu.ac.uk/620591/

Publisher: Taylor \& Francis

DOI: https://doi.org/10.1080/14660970.2014.920625

Please cite the published version 


\title{
Effect of a health improvement pilot programme for older adults delivered by a professional football club: The Burton Albion case study
}

\author{
Andy Pringle ${ }^{1}$, Daniel Parnell, Stephen Zwolinsky, Jackie Hargreaves, Jim McKenna \\ Centre for Active Lifestyles, Carnegie Faculty, Leeds Metropolitan University, LEEDS \\ LS6 3QS, UK.
}

\begin{abstract}
Older-adults are a priority within policy designed to facilitate healthy lifestyles through physical activity. Golden Goal is a pilot programme of physical activity-led health improvement for older-adults 55 years and older. Activities were delivered at Burton Albion Football Club. Sessions involved weekly moderate-intensity exercise sessions including exer-gaming (exercise orientated video-games), indoor bowls, cricket, new age curling, walking football, and traditional board games and skittles. Secondary analysis of data collected through the original programme evaluation of Golden Goal investigated the impact of the intervention on participants. Older-adults completed self-reports for demographics, health-screening/complications and quality of life. Attendees, $n=23$ males (42.6\%) and $n=31$ females $(57.4 \%)$ with a mean age of $69.38( \pm 5.87)(n=40)$, ranging from 55-85 years took part. The mean attendance was $7.73( \pm 3.12)$ sessions for all participants, $(n=51)$. Older-adults with two or more health complications $(n=22,42.3 \%)$ attended fewer sessions on average (6.91 \pm 3.322$)$ compared to those reporting less than two health complications $(8.65 \pm 2.694)$. Self-rated health was higher for women $(87.32 \pm 9.573)$ versus men $(80.16 \pm 18.557)$, although this was not statistically significant $(\mathrm{U}=223.500, p=0.350)$. Results support the potential of football-led health interventions for recruiting older-adults, including those reporting health problems.
\end{abstract}

Key Words: Football, physical activity, health improvement, older adults, intervention

${ }^{1}$ Corresponding author: Email: a.pringle @leedsmet.ac.uk 


\section{Introduction}

Older adults $(\mathrm{OA})$ have been identified as being at risk from a range of chronic conditions. ${ }^{1}$ It has been suggested that physical activity (PA) interventions have the potential to reduce the impact of these conditions on $\mathrm{OA},{ }^{2}$ and this is reflected in key PA policy and guidance. ${ }^{3}$ In doing so, this guidance highlights the importance of adopting a multi-sectorial approach in providing PA opportunities for OA. With those thoughts in mind, professional sports clubs have been recommended as one vehicle for providing lifestyle-based health improvement programmes. Johnman, and colleagues have suggested that delivering lifestyle programmes in professional football clubs for fans and local people are an important contribution to the social and public health of individuals and communities. ${ }^{4}$ This includes OA, who have been specifically targeted through health improvement programmes delivered in, Premier and Football League clubs. ${ }^{5}$

Chronological definitions of ageing do not always accurately reflect the diversity that exists amongst OA. Variations in functional capability and a host of complex needs mean there is a multiplicity of categorisation possible across the OA spectrum. Yet OA have previously been referred to as 'adults over the age of 50 years'. ${ }^{6}$ More recently, definitions have shifted to embrace a relative component of ageing and guidance ${ }^{7}$ provides a more helpful and detailed framework for defining OA based on their PA needs and does so using three categories. (I) Entering into old age/Making activity choices - where the aim is to promote a healthy and active life and compress morbidity. (II) Transitional phase/Increasing the circle of life where the aim is to maintain independence and reduce dependency. (III) Frail older people/Moving into later years - where the aim is to maintain independence and quality of life. This framework is especially important, given the range and complexity of health issues and determinants that OA participants can encounter when initiating and maintaining PA. ${ }^{8}$

Deteriorations in cardiovascular and metabolic health, ${ }^{9}$ low functional capacity, ${ }^{10}$ social isolation, poor mental health ${ }^{11}$ and cognitive decline ${ }^{12}$ represent potentially injurious health consequences of unhealthy ageing which can restrict PA. Yet, a persuasive evidence-base supports the role that PA can play in preventing and/or managing the effects of these conditions. ${ }^{13}$ Despite the compelling case made for PA in both research and policy, at times it 
remains challenging to deliver PA-based programmes within the National Health Service (NHS) as it attempts to deal with reductions in government funding ${ }^{14}$ and rising healthcare costs. ${ }^{15}$ Worse still, OA can now experience increasing financial pressure resulting from existing ill-health ${ }^{16}$ and at the same time, some bespoke preventative health services have been withdrawn. ${ }^{17}$ This holds particular consequences for many lone OA who report facing difficulties in finding and negotiating their own support to continue to live independently. ${ }^{18}$

Existing evidence highlights the beneficial effects of $\mathrm{PA},{ }^{19}$ yet meeting recommended PA levels are rarely achieved. ${ }^{20} \mathrm{OA}$ are encouraged to accumulate at least 150 minutes of moderate intensity activity per-week or around 30 minutes activity on most days of the week. This can be performed in sessions of 10 minutes or more. For OA who are habitually physically active, similar benefits can be achieved through 75 minutes of vigorous intensity PA or a combination of moderate and vigorous PA over the course of a week. Importantly, OA should also undertake activities that help to improve muscle strength on at least two days a week and reduce the amount of time they spend being sedentary. ${ }^{21}$ However, current PA levels in $\mathrm{OA}$ are a matter for concern, with participation rates declining as age increases. Reports based on the previous PA recommendations indicate around $20 \%$ of men and $17 \%$ of women 65-74 met recommended guidelines. ${ }^{22}$ Further, activity reports based on the accelerometery data collected from the 2008 Health Survey for England show that women aged $75+$ achieve two minutes of moderate-vigorous physical activity per-day. While for men aged $75+$, the time spent in moderate-vigorous PA per-day is as little as five minutes. ${ }^{23}$

Given the gap between the PA recommendations and existing behaviour, it is unsurprising that OA report facing significant challenges when attempting to adopt and/or sustain PA participation. Declining PA levels and poor diets make a significant contribution to unhealthy BMI; moreover, overweight OA can be significantly less active than their 'normal' weight counterparts. $^{24}$ Further, low self-efficacy, a lack of social support ${ }^{25}$ and perceived environmental factors ${ }^{26}$ can also combine - or act in isolation - to inhibit participation. Research shows that perceived barriers for outdoor PA participation precede a decline in the mobility levels in community-dwelling OA. ${ }^{27}$ The same evidence base highlights the need to address the concerns of OA regarding safety, distance and access to PA facilities. Further, 
research supports the notion that maintaining functional capacity is likely to be critical for the mental well-being of many OA, ${ }^{28}$ as a degree of community mobility is essential for independent living. ${ }^{29}$ This complex array - and interplay - of factors indicate the scale of the challenge faced by deliverers attempting to encourage OA to adopt and maintain PA.

OA have been 'targeted' as a group for health improvement through health and PA strategies, both in the $\mathrm{UK}^{30}$ and globally. ${ }^{31}$ Previous PA interventions have included walking schemes 32 exercise referral programmes, exercise groups and peer-mentoring ${ }^{33}$ delivered by a range of public agencies. However, while it is important to identify suitable modes of PA, it is also important that the methods used to implement interventions are acceptable to participants. ${ }^{34}$ A recent review of PA interventions with a sample of over 99,000 a-symptomatic adults identified four key design characteristics for promoting PA. ${ }^{35}$ Interventions should be: (I) delivered direct to the participant, (II) use local and familiar settings, (III) adopt behavioural change techniques and methods (IV) involve key exercise leaders in the delivery of programmes. Moreover, contemporary public health guidance for OA compliments this knowledge base. Relevant guidance recommends that deliverers assess the needs of OA. Providers should also offer regular group and/or individual sessions which encourage OA to rehearse activities that support the maintenance of their active daily routines, as well as a flexible and varied menu of PA options to cater for the different needs of OA. ${ }^{36}$

It is interesting that professional football clubs have been used as settings for the delivery of PA-led, health improvement programmes for a number of groups, ${ }^{37}$ including OA. Two bespoke PA-led interventions implemented in professional footballing settings are outlined below. Firstly, the Extra Time programme targeted OA aged 55 years and above with PA-led social inclusion and health-improvement projects delivered nationwide. ${ }^{38}$ Interventions were offered to OA within Premier and Football League club community schemes using club and community facilities and centred on individual and group-based delivery designs. In particular, activities for both men and women, aimed to address key public health priorities, cardiovascular health, reducing social isolation and maintain/improve physical/psychological functioning, three important outcomes for healthy ageing. ${ }^{39}$ Secondly, and with the understanding that older men are at risk of poor health, ${ }^{40}$ the Premier League Men's Health 
programme, was a national suite of 16 interventions delivered in English Premier League and Championship football clubs for adult men. Recruits also included males who were 55 years. Findings support that older men were reached and adopted interventions. Further, men including, older males demonstrated statistically significant improvements for a range of cardio-vascular disease (CVD) risk factors. ${ }^{41}$ Importantly, some participants reported that they did not engage in health improvement interventions led and delivered in traditional healthcare settings. ${ }^{42}$ These two examples demonstrate the potential of football based, PA-led health improvement programmes for reaching and facilitating changes in the health behaviours of OA.

National guidance recommends that behavioural health interventions are evaluated, in order that their impact is assessed and deliverers learn about the effects of such schemes. ${ }^{43}$ This is particularly important, given that to the best of our knowledge, there is a paucity of peer reviewed studies assessing the effect of football-led health-improvement programmes delivered in English football league clubs and aimed specifically at the engagement and health-improvement of OA. With those thoughts in mind, this study set out to investigate the demographic and health profiles of participants attending Golden Goal (GG), a pilot programme of PA-led health improvement for OA delivered by Burton Albion FC. This case study of practice was undertaken using a secondary analysis of data collected as part of a previous local evaluation of the GG programme.

\section{Method}

\section{Intervention context}

Burton Albion FC are located in the town of Burton in East Staffordshire in the English East Midlands and which has a population of 113,583; 19,131 (16.9\%) are residents of retirement age (65+). Data on deprivation shows that East Staffordshire has 70 Lower Layer Super Output Areas (LSOAs - a measure of deprivation). ${ }^{44}$ Consistent with this, adult male life expectancy is lower than the English average in 13 of the 21 wards within East Staffordshire, ${ }^{45}$ while the numbers of hip fractures in the $65+$ age group exceed the national average. ${ }^{46}$ Further, local assessment of health needs highlighted a lack of awareness in OA, of the role of diet and PA in preventing and managing cognitive conditions such as 
dementia. ${ }^{47}$ Local health plans for area over the next four years have endorsed the importance of PA promotion for the purposes of health improvement ${ }^{48}$ including those linked to unhealthy ageing. In line with national guidance ${ }^{49}$ local health needs assessments supported the requirement for preventative health improvement activities for $\mathrm{OA}$ and this was the basis for the GG programme.

Building on the governmental aspiration to generate strong local health partnerships, GG was conceived to address the health needs of OA identified locally. The programme resulted from the combined efforts of Burton Albion Community Trust (BACT) - (the community arm and registered charity of Burton Albion Football Club) - along with local partners and builds upon the concept and novel Extra Time project to reach OA. ${ }^{50}$ To manage the often diverse and complex health needs of OA, ${ }^{51}$ the GG programme aimed to promote positive physical and social opportunities to local participants through a diverse PA-based programme. Considering public health guidance, ${ }^{52}$ which recommends that deliverers provide a range of mixed exercise programmes of moderate intensity in local venues, PA sessions were offered on a weekly basis at the Pirelli Stadium, home to Burton Albion FC. All activities were provided by BACT members of staff with a range of sports coaching qualifications and experience working on community engagement programmes. Activities included exergaming (exercise orientated video-games), indoor bowls, cricket, new age curling, walking football, alongside traditional board games, bingo, table tennis, zumba and skittles. A diverse range of PA options were provided to cater for participants with different interests, fitness levels and abilities. It should be remembered that it is possible for some OA to become at least moderately active through small amounts of PA. As with other community PA interventions aimed at $\mathrm{OA}^{53}$ participants were recruited through a range of local partners and media, including healthcare agencies, the local authority sports development service, local elderly care homes and charities. Adverts were also placed in the local press and club media. The programme was funded by an 'Award for All', a National Lottery grant and forms part of the BACT community engagement plans. ${ }^{54}$ To assess the impact of the programme, a service level evaluation was commissioned by the BACT from a local evaluator. 


\section{Instrumentation and ethics}

Ethical clearance was secured from the research ethics committee at Leeds Metropolitan University to perform a secondary analysis of the data that was collected as part of the original programme evaluation. OA had completed pre-intervention self-report measures at first point of contact. These were usually performed at participant inductions to the programme of GG events. Drawing on approaches and methods established for audiences with low health literacy ${ }^{55}$ questionnaires were completed for demographics (age, gender, post code) and for health screening. The EQ-5D is a quality of life questionnaire and was used within this study, due to its applicability with older populations, providing a simple descriptive profile and a single index value for health status. ${ }^{56}$ EQ-5D includes a vertical visual analogue scale (VAS), which shows 100 as a participant's 'best imaginable health state' and 0 as being their 'worst imaginable health state'. EQ-5D has been used widely, ${ }^{57}$ including with $\mathrm{OA}$ at risk of $\mathrm{CVD}^{58}$ and $\mathrm{OA}$ with mobility impairments. ${ }^{59}$ It has been reported that the measure compares favourably to other similar measures of quality of life. ${ }^{60}$ In this study, EQ-5D was administered both pre- and post- 12-week intervention. Registers were also used to measure attendance at the weekly sessions. All data were collected by the health coaches/instructors who led the activities, and who had been trained by the original evaluator on how to collect the data and to conform to ethical requirements.

\section{Analysis of the data}

Following data preparation, descriptive statistics were used to determine demographic breakdowns and pre-intervention profiles. Independent $t$-tests were used to assess for mean differences in attendance and EQ VAS scores by gender. Mann-Whitney U tests were used to examine differences between attendance rates in participants reporting less than two and two or more health complications. Pre vs. post intervention changes were assessed using crosstabulation and analysed using Wilcoxon signed rank tests (Z). For all inferential tests, a $p$ value of 0.05 or less was taken to be statistically significant. All analysis was performed using the Statistical Package for Social Science (SPSS) version 20. 


\section{Results}

\section{Demographic profile}

Within this pilot project disparities were found in the response rates to the questionnaire for the different variables, Table 1 shows the extent of this loss of data. In total $\mathrm{N}=54$ participants engaged the evaluation of GG and provided data for analysis. The cohort contained $n=23$ males $(42.6 \%)$ and $n=31$ females $(57.4 \%)$. For demographics, data on age was provided by $n=40$ participants, with a mean age of $69.38( \pm 5.87)$ years, ranging 55-85 years. Attendance data confirmed 51 active participants. Attendance at the weekly session ranged from 1 to all 12 occasions, with a mean attendance of $7.73( \pm 3.12)$ sessions. Mean male attendance was $7.90( \pm 3.35)$ sessions, and mean female attendance was $7.60( \pm 3.01)$ sessions. These differences were not statistically significant $\mathrm{t}(49)=0.333, \mathrm{p}=0.741$.

\section{Insert Table 1}

\section{Pre-intervention health screening profiles}

At pre-intervention screening, more participants reported having 'less than two' health complications $(57.7 \%)$ compared to participants reporting 'two or more' (42.3\%). Participants with 'two or more' health complications averaged fewer attendances (6.91 $\pm 3.322)$ than those reporting 'less than two' $(8.65 \pm 2.694)$. This difference was not significant $(\mathrm{U}=208.500, \mathrm{p}=0.073)$.

\section{EQ 5D questionnaire profiles}

Results for the EQ 5D quality of life questionnaire are shown in the following tables. Table 2 shows that the majority of participants $(83 \%)$ reported no problems with mobility at preintervention. This was mirrored at post intervention with $80.9 \%$ reporting no problems with mobility. Statistical analysis revealed no significant changes from pre to post intervention $(\mathrm{Z}=-1.000, p=0.317)$.

Insert Table 2 
Table 3 shows that the majority of participants (91.8\%) reported no problems with self-care at pre-intervention. There was no change in scores at post-intervention and statistical analysis revealed no significant changes from pre to post-intervention $(\mathrm{Z}=0.000, p=1.000)$.

Insert Table 3

Table 4 shows that the majority of participants (87.8\%) reported no problems undertaking usual activities at pre-intervention. There was little change in scores at post-intervention. Statistical analysis revealed no significant changes in ability to perform usual activities from pre to post intervention $(\mathrm{Z}=-1.000, p=0.317)$.

Insert Table 4

Table 5 shows that the majority of participants $(68.1 \%)$ reported no pain/discomfort at preintervention. At post-intervention this figure dropped to 59.6\%. Statistical analysis revealed no significant changes in pain/discomfort from pre to post-intervention $(\mathrm{Z}=-1.414, p=0.157)$.

Insert Table 5

Table 6 shows that the majority of participants (83\%) reported no anxiety/depression at preintervention. At post-intervention this figure improved to $87.2 \%$. Statistical analysis revealed no significant changes in anxiety/depression from pre to post-intervention $(\mathrm{Z}=$ $1.414, p=0.157)$.

Insert Table 6

Results from the EQ VAS question suggest that pre-intervention scores were high (84.43 \pm 14.183 ), especially considering the age of the participants. These scores remained high post-intervention $(84.51 \pm 13.095)$, but there were no statistically significant intervention effects $(\mathrm{Z}=-0.172, p=0.864)$. Although women $(87.32 \pm 9.573)$ self-rated their health as higher than men $(80.16 \pm 18.557)$ at pre-intervention, this difference was not statistically 
significant $t(45)=-1.736 p=0.089$. At post-intervention, men reported slightly higher selfrated health scores compared to pre-intervention $(81.16 \pm 17.270)$. Post-intervention, women reported a slight decline (86.79 \pm 8.946$)$. The differences in EQ VAS scores at post intervention by gender were not statistically significant $t(45)=-1.146 p=0.150$. The men (mean change 1.00), showed a greater intervention effect on EQ VAS scores over the course of the intervention compared to women (mean change -0.54), but the difference in change was not statistically significant $t(45)=0.750 p=0.459$.

\section{Discussion}

Our case study investigated the impact of GG, a pilot programme of PA-led health improvement for OA delivered in Football League Division 2 club, Burton Albion FC.

\section{Demographic and attendance profile of older-adults participating in Golden Goal}

Key findings support the potential of professional football clubs for recruiting both male and female OA into health improvement schemes, suggesting programmes centred in these settings can be acceptable to both men and women. The GG pilot project recruited a diverse age group with different health and PA needs, including, participants both entering old age and in the transitional stage of ageing. ${ }^{61}$ Moreover, recruits attended almost two thirds of scheduled sessions. Adoption outcomes for GG are important, as both these categories of OA have been identified as important in public health guidance. Further, the GG programme of activities play an important role in helping OA to initiate and/or maintain their existing activity levels as recommended in such guidance ${ }^{62}$ as well as in local PA strategies. ${ }^{63}$

Concerns have been expressed over how to recruit older men into community health improvement programmes ${ }^{64}$ and research has shown that female attendees can outnumber their male counterparts as much as $2: 1{ }^{65}$ In comparison, attendance ratios at GG differed considerably. Notwithstanding a low level of overall recruitment from an evaluation perspective, once engaged, older male attendees were no less likely to miss a session than women. Importantly, male recruits reported lower initial self-rated health when compared to females, yet these outcomes were less divergent post-intervention. Results support the notion 
that older men will attend health improvement programmes when these are deemed acceptable to them, including those delivered in professional football club settings as reported elsewhere. ${ }^{66}$ Similarly, locating a programme of physical and social activities in a professional football club was not a barrier to the engagement of female attendees. PA provision like that shown in GG, offers OA the opportunity to attend activities with their partners and/or in mixed gender groups of friends. Further, supportive social networks that can be generated by such programmes are important in facilitating the maintenance of OA PA levels and recommended in guidance. ${ }^{67}$

\section{Health profiles of older-adults participating in Golden Goal}

Results also indicate, the intervention attracted a relatively healthy cohort who typically reported few health complications. Those reporting fewest health complications were more likely to attend a greater number of activity sessions than those reporting multiple complications, which could imply that health problems can limit participation in PA. Existing guidance indicates that OA can be fearful that PA may act to worsen existing health conditions ${ }^{68}$ and GG recruited a substantial minority of OA reporting health complications. Men also reported lower self-rated health when compared to their female counterparts. Given that PA can help manage a number of chronic conditions as previously discussed, the recruitment of these constituents to the programme is an important public health outcome. Owing to the absence of PA data, we have no means of confirming that GG-related PA initiated new activity or if the programme replaced existing PA modes. This limitation means that the programme cannot confirm having reached the inactive priority groups identified highlighted in the local evidence base. ${ }^{69}$ That said, there is Public Health value in maintaining the PA levels of 'already-active OA' and both National guidance ${ }^{70}$ and local health strategies identify the importance of recruiting groups with a range of PA levels, not solely inactive OA into PA programmes. ${ }^{71}$ This is because active participants not only create an activity group for others to join, but also can model PA participation for others and support those individuals who are new or returning to PA. ${ }^{72}$ 


\section{Intervention design and impact on adoption profiles}

Including a process evaluation that involved participants would have helped to confirm the extent to which the design of the programme influenced engagement profiles. In the absence of this, the deployment of four key, intervention design characteristics may help to explain the engagement profiles seen in this study. Firstly, delivering activities within the Pirelli Stadium (home of Burton Albion Football Club) could have been considered to capitalise on its visibility and it being a local and familiar setting for local potential participants. ${ }^{73}$ Secondly, providing a range of exercise modes and delivery options appears to offer an advantageous approach to recruiting and catering for a diverse range of OA with different PA interests and levels of ability. ${ }^{74}$ Thirdly and contrastingly, more attention may have been paid to establishing informal social interaction, so as to enhance both levels of recruitment and engagement in the programme. This includes the use of captive audiences and social networks for reaching those hard-engage OA, including sedentary and BME participants through 'word of mouth'. In the interventions we featured earlier, a number of clubs performed outreach work with BME groups and these offer potential routes for clubs to connect with these constituents. ${ }^{75}$ Fourthly, the provision of PA in a fun, flexible and enjoyable form appears to influence recruitment and maintenance and is an important design consideration. ${ }^{76}$ Finally, it is also important to reflect on the scale of this pilot intervention versus the numbers of recruits achieved by the more prestigious clubs - and better funded health evaluation - associated with the Premier League Health programme. ${ }^{77}$ It is unclear whether the prestige, the 'club badge', funding or recruitment approaches were key issues in effecting lower level recruitment into the GG programme, even allowing for the widespread local need for improving the PA and health profiles of OA. As such, further investigations are needed and form the scope of future research activity on this intervention.

\section{Important considerations for promoting physical activity with older-adults}

Guidance informs us that OA participants are likely to have a diverse range of PA profiles and present with varied needs and to a degree, this has emerged in this study. New commissioning arrangements in Public Health raise the possibility that more commercial and not-for-profit providers, including professional football clubs will be seeking to offer health 
improvement opportunities for specific groups with distinctive health needs linked to lack of PA. Considerable work may be needed to prepare these staff for ensuring that this work and any investment that supports it - makes a genuine contribution to better Public Health. ${ }^{78}$ Inactive and OA suffering from health problems face challenges in becoming active. As such, the recruitment of these individuals is likely to be challenging to both the participants and providers of health improvement programmes. Those staff involved in the delivery of health improvement programmes in football clubs will need to be well prepared to recruit and then cater for OA who present at interventions like GG. Going forward, training and education is an important component when enhancing the preparedness of the providers of health improvement programmes for OA.

While lessons can be drawn for what helped the current group of participants to adopt the GG programme, Public Health guidance offers further considerations when planning and implementing PA interventions. One consideration of uppermost importance, is mapping the needs of different groups of $\mathrm{OA}^{79}$ including, those sedentary and inactive participants. The needs of these individuals are likely to be different from those constituents who meet the PA recommendations, not least because they often have little behavioural success on which to build. It is recommended that the needs of different groups of OA are carefully plotted against the design and the delivery of interventions aimed at meeting these needs. ${ }^{80}$ In doing so, it is fundamental to involve OA and where appropriate their careers and supporters in this process for a number of reasons. ${ }^{81}$ Firstly, they will provide important insights on how to identify needs, plan, implement and evaluate PA and health improvement interventions. Secondly, they can build a picture of the complex interplay between the determinants PA participation. Many of these factors may seem unimportant to providers with limited experience, either in promoting PA or working with OA. Needs assessment is an on-going process and delivers should take the opportunity to consult with the captive audiences of OA as interventions 'get under way', as well as speaking to those whose attendance 'drops off'. In reality, such approaches provide invaluable information for shaping the delivery of bespoke health improvement programmes for potential participants, including $\mathrm{OA}^{82}$ and those groups reported as 'hard-to-engage' in health interventions. ${ }^{83}$ 


\section{Limitations and strengths of this research}

The limitations emerging from this study, including those inherent in the original programme evaluation strategy signal the need for further learning and provide important 'take away' messages. Earlier collaboration in the evaluation process would have reduced the impact of these factors. In line with guidance, findings endorse the importance of engaging appropriate evaluation skills at any early development stage. Nonetheless, these limitations provide valuable considerations for the development of future monitoring strategies, including those used in GG and other football-led health improvement programmes. Limitations include the use of self-report data, which was collected for a period of 12 weeks. A longer time period closer to six months - is needed to identify the impact of the programme on sustaining both engagement and PA levels. Other limitations include the lack of 'blind' data collection (where independent evaluators collect data). While this is recommended, and will heighten data quality, it is not always possible in partnership evaluation designs which may predominate in community-based evaluations. ${ }^{84} \mathrm{~A}$ further limitation was the absence of a measure of PA status, while the inclusion of a simple 'new or replacement' question would have allowed researchers to identify the extent to which recruits were new to PA or were transferring from existing PA participation. Further, the small sample size was also a limiting factor in this study. Strengths included the use of validated instrumentation and a strong desire and commitment on behalf the club, to evaluate and learn from the outcomes emerging from this programme, so that delivery and evaluation strategies could be refined and enacted. As such, the outcomes emerging from this study provide helpful insights on what and what not to do.

\section{Conclusion}

Both male and female OA attended GG, a PA-led health improvement pilot programme delivered in/by a professional football club. The sample appears to predominantly healthy, but those reporting health complexities were also engaged. Participants with two or more health complications attended fewer sessions on average compared to those reporting less than two health complications, while men had lower self-rated health when compared to women. Our paper highlights some of the considerations when planning, delivering and evaluating PA interventions delivered to $\mathrm{OA}$ in footballing settings. Further research is 
needed to explore the potential of professional football clubs in engaging inactive OA into health-improvement programmes, including changes in health profiles and an understanding of what makes such programmes acceptable to different groups of OA.

\section{Acknowledgements}

In preparing this manuscript the authors most gratefully acknowledge the participants and staff of Burton Albion FC and their partners who generously contributed to and supported this research. 


\section{Notes:}

${ }^{1}$ BHF, Active for Later life.

${ }^{2}$ Clark et al., 'Effectiveness of a Lifestyle Intervention in Promoting the Well-being of independently Living Older People' and Pringle et al., 'Cost Effectiveness of Interventions to Improve Moderate Physical-Activity'.

${ }^{3}$ Department of Health. Start Active, Stay Active.

${ }^{4}$ Johnman et al., 'The Beautiful Game'.

${ }^{5}$ Football Foundation, Extra-Time: Evaluation Summary Report.

${ }^{6}$ WHO, Health Statistics and Information.

${ }^{7}$ BHF, Active for Later life.

${ }^{8} \mathrm{BHF}$, Active for Later life.

${ }^{9}$ Kahn et al., 'The Impact of Prevention on Reducing the Burden of Cardiovascular Disease'.

${ }^{10}$ Stathi, ‘Populations: Older People and Physical Activity'.

${ }^{11}$ Cornwell and Waite, 'Social Disconnectedness, Perceived Isolation and Health Among Older Adults'.

${ }^{12}$ Wilson et al. 'Loneliness and Risk of Alzheimer Disease'.

${ }^{13}$ Brown et al., 'Physical Activity and All-Cause Mortality in Older Women and Men'.

${ }^{14}$ Wray. 'The Impact of the Financial Crisis on Nurses and Nursing'.

${ }^{15}$ Wang et al., 'Health and Economic Burden of the Projected Obesity Trends in the USA and the UK'.

${ }^{16}$ Hill et al., Managing Resources in Later Life.

${ }^{17}$ DCSM, News Stories: Free Swimming Programme.

${ }^{18}$ Hill et al., Managing Resources in Later Life. 
${ }^{19}$ Department of Health, Start Active, Stay Active.

${ }^{20}$ The Information Centre for Health and Social Care. Statistics on Obesity, Physical Activity and Diet in England 2010.

${ }^{21}$ BHF. Key Facts: Older People.

${ }^{22}$ BHF. Current Physical Activity Levels in Older Adults.

23 The Information Centre for Health and Social Care. Health Survey for England. Physical activity and fitness.

${ }^{24}$ Davis et al., 'Objectively Measured Physical Activity in a Diverse Sample of Older Urban UK Adults'.

${ }^{25}$ Marcus and Forsyth. Motivating People to be Physically Active.

${ }^{26}$ Booth et al., 'Social-Cognitive and Perceived Environment Influences Associated with Physical Activity in Older Australians'.

${ }^{27}$ Rantakokko et al., 'Perceived Barriers in the Outdoor Environment and Development of Walking Difficulties in Older People'.

${ }^{28}$ Netz et al., 'Physical activity and psychological wellbeing in advanced age'.

${ }^{29}$ Stathi, Populations: Older People and Physical Activity'.

${ }^{30} \mathrm{DH}$, Healthy Lives, Healthy People.

${ }^{31}$ WHO, Global Strategy on Diet, Physical Activity and Health.

32 Dawson et al., 'Perceived Barriers to Walking in the Neighbourhood Environment and Change in Physical Activity Levels Over 12 months'.

33 Pringle et al., 'Cost Effectiveness of Interventions to Improve Moderate PhysicalActivity.

34 Pringle et al., 'Delivering Men's Health Interventions in English Premier League Football Clubs'.

${ }^{35}$ Conn et al., 'Interventions to Increase Physical Activity among Healthy Adults'.

${ }^{36}$ NICE, Occupational Therapy and Physical Activity Interventions.

${ }^{37}$ Parnell et al., 'Football in the Community Schemes'. 
${ }^{38}$ Football Foundation: Extra Time

${ }^{39}$ BHF. Active for Later Life and Department of Health. Start Active, Stay Active.

${ }^{40}$ European Commission. The State of Men's Health in Europe.

${ }^{41}$ Pringle et al., Effect of a National Programme of Men's Health Delivered in English Premier League Football Clubs' and Pringle et al., 'Health Improvement for Men and Hard-to-Engage-Men Delivered in English Premier League Football Clubs'.

${ }^{42}$ Robertson et al., 'It's Fun, Fitness, Football Really'.

${ }^{43}$ NICE. Behaviour Change.

${ }^{44}$ East Staffordshire Borough Council, 2011 Census Data: East Staffordshire.

${ }^{45}$ NHS East Staffordshire, Clinical Commissioning Group. East Staffordshire, Enhanced Joint Strategic Needs Assessment.

${ }^{46}$ East Staffordshire Borough Council 2011 Census Data: East Staffordshire.

${ }^{47}$ NHS East Staffordshire, Clinical Commissioning Group East Staffordshire, Enhanced Joint Strategic Needs Assessment.

${ }^{48}$ NHS East Staffordshire Clinical Commissioning Group. East Staffordshire Delivery of Change Plan: 2012-16.

${ }^{49}$ NICE, Occupational Therapy and Physical Activity Interventions.

${ }^{50}$ Football Foundation, Extra Time.

${ }^{51} \mathrm{BHF}$, Active for Later Life.

${ }^{52} \mathrm{BHF}$, Active for Later Life.

${ }^{53}$ Sport England, Learning from LEAP.

${ }^{54}$ Burton Albion Community Trust. Golden Goal.

${ }^{55}$ Sport England, Learning from LEAP.

56 Euroqol. EQ-5D ${ }^{T M}$ A Standardised Instrument for use as a Measure of Health Outcome. 
57 Brook et al., 'The Measurement and Valuation of Health Status Using EQ-5D: A European Perspective'.

${ }^{58}$ Sahlen et al., 'Health Coaching to Promote Healthier Lifestyle among Older People at Moderate Risk for Cardiovascular Diseases, Diabetes and Depression'.

${ }^{59}$ Davis et al., 'Exploration of the Association between Quality of Life, Assessed by the EQ-5D and ICECAP-O, and Falls Risk, Cognitive Function and Daily Function, in Older Adults with Mobility Impairments'.

${ }^{60}$ Barton et al., 'A Comparison of the Performance of the EQ-5D and SF-6D for Individuals aged $\geq 45$ years'.

${ }^{61} \mathrm{BHF}$, Active for Later Life.

${ }^{62} \mathrm{BHF}$, Active for Later Life.

${ }^{63}$ East Staffordshire Borough Council, Community Sport and Physical Activity Network, 2012-13 Action Plan.

${ }^{64}$ European Commission. The State of Men's health in Europe and Pringle et al., 'Health Improvement for Men and Hard-to-Engage-Men Delivered in English Premier League Football Clubs'.

65 Pringle et al., 'Cost Effectiveness of Interventions to Improve Moderate PhysicalActivity'.

${ }^{66}$ Football Foundation, Extra Time.

${ }^{67} \mathrm{BHF}$, Active for Later Life.

${ }^{68} \mathrm{BHF}$, Active for Later Life.

${ }^{69}$ East Staffordshire Borough Council, Community Sport and Physical Activity Network, 2012-13 Action Plan.

${ }^{70} \mathrm{BHF}$, Active for Later Life.

${ }^{71}$ East Staffordshire Borough Council, Community Sport and Physical Activity Network, 2012-13 Action Plan.

72. Pringle et al., 'Cost Effectiveness of Interventions to Improve Moderate PhysicalActivity'. 
${ }^{73}$ Conn et al., 'Interventions to Increase Physical Activity among Healthy Adults'.

${ }^{74} \mathrm{BHF}$, Active for Later Life.

${ }^{75}$ Pringle et al., Effect of a National Programme of Men's Health Delivered in English Premier League Football Clubs'.

76 Robertson et al., 'It's Fun, Fitness, Football Really' and BHF, Active for Later Life.

${ }^{77}$ Pringle et al., Effect of a National Programme of Men's Health Delivered in English Premier League Football Clubs'

${ }^{78}$ Pringle et al., 'Health Improvement and Professional Football: Players on the Same Side'.

${ }^{79}$ NICE, Occupational Therapy and Physical Activity Interventions.

${ }^{80}$ Ransdell et al., Developing Effective Physical Activity Programmes.

${ }^{81}$ NICE, Occupational Therapy and Physical Activity Interventions and BHF, Active for Later Life.

${ }^{82}$ Pringle et al., 'Working with Black and minority ethic elders in planning a DVD resource to promote physical activity'.

${ }^{83}$ Pringle et al., 'Health Improvement for Men and Hard-to-Engage-Men Delivered in English Premier League Football Clubs'.

${ }^{84}$ Pringle et al., 'Health Improvement for Men and Hard-to-Engage-Men Delivered in English Premier League Football Clubs'. 


\section{References}

Barton, G.R., T.H. Sach, A.J. Avery, C. Jenkinson, M. Doherty, D., and Whynes, K. 'A Comparison of the Performance of the EQ-5D and SF-6D for Individuals Aged > 45 Years'. Health Economics 17 (2008): 815-32.

Booth, M., N. Owen, A. Bauman, O. Clavisi, and E. Leslie. 'Social-Cognitive and Perceived Environment Influences Associated with Physical Activity in Older Australians'. Preventative Medicine 31 (2000): 15-22.

British Heart Foundation. Active for Later Life. London: BHF, 2009. http://www.bhfactive.org.uk/older-adults-resources-and-publicationsitem/78/index.html (accessed August 1, 2013).

British Heart Foundation Current Physical Activity levels in Older Adults: Fact Sheet, 2012. Available at: file://C:/Users/Pring102/Downloads/Physical\%20Activity\%20Older\%20Adults\%20A W\%20(1).pdf (accessed March 17, 2014).

British Heart Foundation, National Centre. Key facts: Older People. Loughborough: British Heart Foundation, 2013. http://www.bhfactive.org.uk/older-adults-keyfacts/index.html (accessed 1 August, 2013).

Brook, R., R.F. Rabin, and F Charro. The Measurement and Valuation of Health Status using EQ-5D: A European perspective. Dordrecht: Kluwer Academic Publishers, 2003.

Brown, W. D., D. McLaughlin, J. Leung, K. McCaul, L. Flicker, O. Almeida, G. Hankey, D. Lopez, and A. Dobson. 'Physical Activity and All-Cause Mortality in Older Women and Men'. British Journal of Sports Medicine 46 (2012): 664-668.

Burton Albion Community Trust. Golden Goal, BACT, Burton, 2013 http://burtonalbioncommunitytrust.co.uk/courses/golden-goal-over-50s-activityprogramme/ (accessed August 1, 2013). 
Clark, F., J. Jackson, M. Carlson, M. CP. Chou, B. Cherry, M. Jorgan-Marsh, et al., 'Effectiveness of a Lifestyle Intervention in Promoting the Well-being of Independently Living Older People: Results of the Well Elderly 2 Randomised Controlled Trial'. Journal of Epidemiology and Community Health 66 (2012): 782-90.

Conn, V., A. Hafdahl, and D. Mehr. 'Interventions to Increase Physical Activity among Healthy Adults: Meta-Analysis of Outcomes'. American Journal of Public Health 101 (2011): 751-58.

Cornwell, E., and L. Waite. 'Social Disconnectedness, Perceived Isolation and Health among Older Adults'. Journal of Health and Social Behaviour 50 (2009): 31-48.

Davis, J.C., S. Bryan, R. McLeod, J. Rogers, K. Khan, T. Liu-Ambrose. 'Exploration of the Association between Quality of Life, Assessed by the EQ-5D and ICECAP-O, and Falls Risk, Cognitive Function and Daily Function, in Older Adults with Mobility Impairments'. BMC Geriatrics, 12 (2012). http://www.biomedcentral.com/14712318/12/65 (accessed 24 September, 2013).

Davis, M., K. Fox, M. Hillsdon, D. Sharp, J. Coulson, and J. Thompson. 'Objectively Measured Physical Activity in a Diverse Sample of Older Urban UK Adults'. Medicine \& Science in Sports \& Exercise 4 (2011): 647-54.

Dawson, J., M. Hillsdon, I. Boller, and C. Foster. 'Perceived Barriers to Walking in the Neighbourhood Environment and Change in Physical Activity Levels over 12 months'. British Journal of Sports Medicine 41 (2007): 562-68.

Department for Culture, Media and Sport. News Stories: Free Swimming Programme. London: Department for Culture, Media and Sport, 2013. http://www.culture.gov.uk/news/news_stories/7193.aspx (accessed September 24, 2013).

Department of Health. Healthy Lives, Healthy People: Our Strategy for Public Health in England. London: Department of Health, 2011. 
http://www.dh.gov.uk/en/Publicationsandstatistics/Publications/PublicationsPolicyAnd Guidance/DH_121941. (accessed August 1, 2013).

Department of Health. Start Active, Stay Active: A Report on Physical Activity for Health from the Four Home Countries Chief Medical Officers. London: Crown, 2011. http://www.dh.gov.uk/prod_consum_dh/groups/dh_digitalassets/documents/digitalasset /dh_128210.pdf (accessed 24 September 24, 2013).

East Staffordshire Borough Council. 2011 Census Data: East Staffordshire, East $\begin{array}{llll}\text { Staffordshire } & \text { Borough } & \text { Council, }\end{array}$ http://www.eaststaffsbc.gov.uk/Services/2011\%20Census/2011CensusSecondReleaseE astStaffsPopulationSummary.pdf (accessed September 23, 2013).

East Staffordshire Borough Council. Community Sport and Physical Activity Network, 2012-13 Action Plan. East Staffordshire Borough Council, 2013. http://www.eaststaffsbc.gov.uk/Services/SportEastStaffs/Pages/CommunitySportandPh ysicalActivityNetwork.aspx (accessed September 9, 2013).

European Commission. The State of Men's Health in Europe. Luxembourg: European Commission, 2011:

http://ec.europa.eu/health/population_groups/docs/men_health_report_en.pdf. (accessed January 24, 2012).

Euroqol. EQ-5D ${ }^{T M}$ A Standardised Instrument for Use as a Measure of Health Outcome. http://www.euroqol.org/home.html (accessed September 24, 2013).

Football Foundation. Extra-Time: Evaluation Summary Report, London, Football Foundation, 2011. http://www.footballfoundation.org.uk/our-schemes/extra-time/extratime-summary-report/?assetdet240618=29315 (accessed August 1, 2013).

Hill, K., L. Sutton, and L. Cox. Managing Resources in Later Life: Older People's Experience of Change and Continuity. York: Joseph Rowntree Foundation. http://www.jrf.org.uk/system/files/older-people-resourcesFULL.pdf （accessed September 12, 2013). 
Johnman, C., F. Sim, and P. Mackie, P. 'The Beautiful Game'. Public Health 127 (2013): 697-98.

http://www.publichealthjirnl.com/article/PIIS0033350613002448/fulltext (accessed September 10, 2013).

Kahn, R., R.M. Robertson, R. Smith, and D. Eddy. 'The Impact of Prevention on Reducing the Burden of Cardiovascular Disease'. Circulation 118 (2008): 576-85. http://circ.ahajournals.org/cgi/content/full/118/5/576 (accessed September 9, 2013).

Marcus, B., and L. Forsyth. Motivating People to be Physically Active, 2nd Edition. Champaign, Illinois: Human Kinetics, 2009.

National Institute of Health and Clinical Excellence. Occupational Therapy and Physical Activity Interventions to Promote the Mental Wellbeing of Older Adults in Primary Care and Residential Care. London: National Institute of Health and Clinical Excellence, 2004. http://www.nice.org.uk/nicemedia/pdf/ph16guidance.pdf (accessed September 24, 2013).

National Institute of Health and Clinical Excellence. The Most Appropriate Means of Generic and Specific Interventions to Support Attitude Behavioural Change at Population and Community Levels. London: National Institute of Health and Clinical Excellence, 2007. http://www.nice.org.uk/PH6 (accessed September 24, 2013).

Netz, Y., M. Wu, B. Becker, and G. Tenenbaum. 'Physical Activity and Psychological Wellbeing in Advanced Age: A Meta Analysis of Intervention Studies'. Psychology and Ageing 20 (2005): 272-84.

NHS East Staffordshire Clinical Commissioning Group. East Staffordshire Delivery of Change Plan: 2012-16. NHS East Staffordshire, 2012. http://www.eaststaffsccg.nhs.uk/strategies (accessed September 24, 2013).

NHS East Staffordshire, Clinical Commissioning Group. East Staffordshire, Enhanced Joint Strategic Needs Assessment (e-JSNA) Submission, 2012. 
http://www.eaststaffsccg.nhs.uk/search?term=joint+strategic+needs\&search=Search\&s earchType=all (accessed September 24, 2013).

Parnell, D., G. Stratton, B. Drust., and D. Richardson. 'Football in the Community Schemes: Exploring the Effectiveness of an Intervention in Promoting Positive Healthful Behaviour Change'. Soccer and Society 14 (2013): 35-51.

Pringle, A., K. Marsh, N. Gilson, J. McKenna, and C. Cooke. 'Cost effectiveness of Interventions to Improve Moderate Physical-Activity: A study in nine UK sites'. Health Education Journal 69 (2010): 211-24.

Pringle, A., J. McKenna, and A. Smith. 'Working with Black and Minority Ethic Elders in Planning a DVD Resource to Promote Physical Activity'. Journal of Sport and Exercise Science 27 (2010): S59-S60.

Pringle, A., J. McKenna, and S. Zwolinsky. 'Health Improvement and Professional Football: Players on the Same Side'. Journal of Policy Research in Tourism, Leisure and Events 5 (2013): 207-12.

Pringle, A., S. Zwolinsky, J. McKenna, A. Daly-Smith, S. Robertson, and A. White. 'Effect of a National Programme of Men's Health Delivered in English Premier League Football Clubs'. Public Health 127 (2013): 18-26.

Pringle, A., S. Zwolinsky, J. McKenna, A. Daly-Smith, S. Robertson, and A. White. 'Delivering men's Health Interventions in English Premier League Football Clubs: Key Design Characteristics'. Public Health 127 (2013): 717-726.

Pringle, A., S. Zwolinsky, J. McKenna, A. Daly-Smith, S. Robertson and A. White. Health Improvement for Men and Hard-to-Engage-Men Delivered in English Premier League Football Clubs. Health Education Research (2014): doi:10.1093/her/cyu009.

Ransdell, B., K. Dinger, J. Huberty, and K. Miller. Planning and Evaluating Physical Activity Programmes. Developing Effective Physical Activity Programmes, 13-21. Champaign: Illinois, Human Kinetics, 2009. 
Rantakokko, M., S. Iwarsson, M. Manty, R. Leinonen, and T. Rantanen. 'Perceived Barriers in the Outdoor Environment and Development of Walking Difficulties in Older People'. Age and Ageing 41 (2012): 118-121.

Robertson, S., S. Zwolinsky, A. Pringle, J. McKenna, A. Daly-Smith, and. A. White. ' "It's Fun, Fitness and Football Really" A Process Evaluation of a Football Based Health Intervention for Men'. Qualitative Research in Sport Exercise and Health 5 (2013): 419-39.

Sahlen, K-G., H. Johansson, L. Nyström, and L., Lindholm. 'Health Coaching to Promote Healthier Lifestyle Among Older People at Moderate Risk for Cardiovascular Diseases, Diabetes and Depression: A Study Protocol for a Randomized Controlled

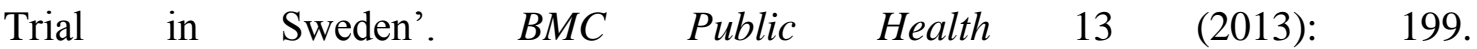
http://www.biomedcentral.com/1471-2458/13/199. (accessed September 25, 2013).

Sport England. Learning from LEAP. London, Sport England, 2006. http://webarchive.nationalarchives.gov.uk/20130107105354/http://www.dh.gov.uk/pro d_consum_dh/groups/dh_digitalassets/@dh/@en/documents/digitalasset/dh_063822.pd f (accessed February 4, 2014).

Stathi, A. Populations: Older People and Physical Activity. In Physical Activity and Health Promotion: Evidence Based Approaches to Practice. ed. L. Dugdill, D. Crone, and R. Murphy, 2009, 174-197. London: Wiley-Blackwell.

The Information Centre for Health and Social Care. Health Survey for England. Physical Activity and Fitness: Summary of Key Findings, 2008. London: The Information Centre for Health and Social Care, 2009. https://catalogue.ic.nhs.uk/publications/public-health/surveys/heal-surv-phys-acti-fitneng-2008/heal-surv-phys-acti-fitn-eng-2008-rep-v1.pdf (accessed 24 September, 2013).

The Information Centre for Health and Social Care. Statistics on Obesity, Physical Activity and Diet in England 2010. London: The Information Centre for Health and Social

Care. 
http://www.ic.nhs.uk/webfiles/publications/opad10/Statistics_on_Obesity_Physical_Ac tivity_and_Diet_England_2010.pdf; 2010. (accessed February 20, 2013).

Wang, Y., K. McPherson, T. Marsh, S. Gortmaker, and M. Brown. 'Health and Economic Burden of the Projected Obesity Trends in the USA and the UK'. Lancet 378 (2011): 815-25.

Wilson, R., K. Krueger, S. Arnold, J. Schneider, J. Kelly, L. Barnes, Y. Tang, and D. Bennett. 'Loneliness and Risk of Alzheimer Disease'. JAMA Psychiatry 64 (2007): 234-40. http://archpsyc.jamanetwork.com/article.aspx?articleid=482179 (accessed September 24, 2013).

World Health Organisation. Global Strategy on Diet, Physical Activity and Health. Geneva, World Health Organisation, 2004. http://www.who.int/dietphysicalactivity/strategy/eb11344/strategy_english_web.pdf (accessed August 24, 2013).

World Health Organisation. Health Statistics and Information. Definitions of an Older Person, 2013. Geneva: World Health Organisation. http://www.who.int/healthinfo/survey/ageingdefnolder/en/ (accessed September 24, 2013).

Wray, J. 'The Impact of the Financial Crisis on Nurses and Nursing'. The Journal of Advanced Nursing 69 (2013): 497-99. 
Tables

Table 1: The total number and percentage of participant's response rates to each variable

\begin{tabular}{lcc}
\hline & $\begin{array}{c}\text { Total Number of } \\
\text { Respondents }\end{array}$ & $\begin{array}{c}\text { Percentage of Total } \\
\text { Respondents }\end{array}$ \\
\hline Demographics & & $\mathrm{n}=54 / 54$ \\
Gender & $\mathrm{n}=40 / 54$ & $100 \%$ \\
Age & $\mathrm{n}=51 / 54$ & $74 \%$ \\
Attendance at Sessions & $\mathrm{n}=52 / 54$ & $94 \%$ \\
Health Complications & & $96 \%$ \\
EQ 5D & & \\
EQ 5D Mobility Pre-Intervention & $\mathrm{n}=50 / 54$ & \\
EQ 5D Mobility Post-Intervention & $\mathrm{n}=47 / 54$ & $93 \%$ \\
EQ 5D Self Care Pre-Intervention & $\mathrm{n}=49 / 54$ & $87 \%$ \\
EQ 5D Self Care Post-Intervention & $\mathrm{n}=49 / 54$ & $91 \%$ \\
EQ 5D Usual Activities Pre-Intervention & $\mathrm{n}=49 / 54$ & $91 \%$ \\
EQ 5D Usual Activities Post-Intervention & $\mathrm{n}=49 / 54$ & $91 \%$ \\
EQ 5D Pain/Discomfort Pre-Intervention & $\mathrm{n}=47 / 54$ & $91 \%$ \\
EQ 5D Pain/Discomfort Post-Intervention & $\mathrm{n}=49 / 54$ & $87 \%$ \\
EQ 5D Anxiety/Depression Pre- & $\mathrm{n}=47 / 54$ & $91 \%$ \\
Intervention & & $87 \%$ \\
EQ 5D Anxiety/Depression Post- & $\mathrm{n}=47 / 54$ & \\
Intervention & & $87 \%$ \\
& & \\
$\boldsymbol{E} \boldsymbol{Q}$ VAS & & \\
EQ VAS Pre-Intervention & $\mathrm{n}=47 / 54$ & $87 \%$ \\
EQ VAS Post-Intervention & $\mathrm{n}=47 / 54$ & $87 \%$ \\
\hline
\end{tabular}

Table 2: Pre vs. Post intervention Scores for EQ-5D for Mobility

\begin{tabular}{c|c|ccc|c}
\hline \multirow{2}{*}{} & \multicolumn{3}{|c|}{ Post Intervention n (\%) } & \\
\cline { 3 - 5 } \multicolumn{2}{c|}{} & No Problems & $\begin{array}{c}\text { Some } \\
\text { Problems }\end{array}$ & $\begin{array}{c}\text { Extreme } \\
\text { Problems }\end{array}$ & Total \\
\hline \multirow{2}{nnyyy}{} & No Problems & $38(97.4)$ & $1(2.6)$ & $0(0.0)$ & $\mathbf{3 9}(\mathbf{8 3 . 0})$ \\
& Some Problems & $0(0.0)$ & $8(100)$ & $0(0.0)$ & $\mathbf{8}(\mathbf{1 7 . 0})$ \\
\hline & $\begin{array}{c}\text { Extreme } \\
\text { Problems }\end{array}$ & $0(0.0)$ & $0(0.0)$ & $0(0.0)$ & $\mathbf{0}(\mathbf{0 . 0})$ \\
\hline & Total & $\mathbf{3 8 ( 8 0 . 9 )}$ & $\mathbf{9 ( 1 9 . 9 )}$ & $\mathbf{0 ( 0 . 0 )}$ & $\mathbf{4 7}(\mathbf{1 0 0})$ \\
\hline
\end{tabular}


Table 3: Pre vs. Post intervention Scores for EQ-5D for Self-Care

\begin{tabular}{|c|c|c|c|c|c|}
\hline & \multicolumn{3}{|c|}{ Post Intervention n (\%) } & \multirow[b]{2}{*}{ Total } \\
\hline & & No Problems & $\begin{array}{c}\text { Some } \\
\text { Problems }\end{array}$ & $\begin{array}{l}\text { Extreme } \\
\text { Problems }\end{array}$ & \\
\hline \multirow{4}{*}{ 乞 } & No Problems & $45(100)$ & $0(0.0)$ & $0(0.0)$ & $45(91.8)$ \\
\hline & Some Problems & $0(0.0)$ & $4(100)$ & $0(0.0)$ & $4(8.2)$ \\
\hline & $\begin{array}{l}\text { Extreme } \\
\text { Problems }\end{array}$ & $0(0.0)$ & $0(0.0)$ & $0(0.0)$ & $\mathbf{0}(\mathbf{0 . 0})$ \\
\hline & Total & $45(91.8)$ & $4(8.2)$ & $\mathbf{0}(\mathbf{0 . 0})$ & $49(100)$ \\
\hline
\end{tabular}

Table 4: Pre vs. Post intervention Scores for EQ-5D for Usual Activities

\begin{tabular}{|c|c|c|c|c|c|}
\hline & & \multicolumn{3}{|c|}{ Post Intervention n (\%) } & \multirow[b]{2}{*}{ Total } \\
\hline & & No Problems & $\begin{array}{c}\text { Some } \\
\text { Problems }\end{array}$ & $\begin{array}{l}\text { Extreme } \\
\text { Problems }\end{array}$ & \\
\hline \multirow{4}{*}{ 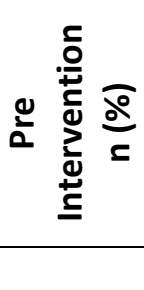 } & No Problems & $42(97.7)$ & $1(2.3)$ & $0(0.0)$ & $43(87.8)$ \\
\hline & Some Problems & $0(0.0)$ & $6(100)$ & $0(0.0)$ & $6(12.2)$ \\
\hline & $\begin{array}{l}\text { Extreme } \\
\text { Problems }\end{array}$ & $0(0.0)$ & $0(0.0)$ & $0(0.0)$ & $0(0.0)$ \\
\hline & Total & $42(85.7)$ & $7(14.3)$ & $0(0.0)$ & $49(100)$ \\
\hline
\end{tabular}

Table 5: Pre vs. Post intervention Scores for EQ-5D for Pain/Discomfort

\begin{tabular}{|c|c|c|c|c|c|}
\hline & & \multicolumn{3}{|c|}{ Post Intervention n (\%) } & \multirow[b]{2}{*}{ Total } \\
\hline & & No Problems & $\begin{array}{c}\text { Some } \\
\text { Problems }\end{array}$ & $\begin{array}{c}\text { Extreme } \\
\text { Problems }\end{array}$ & \\
\hline \multirow{4}{*}{ 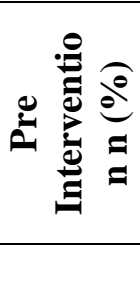 } & No Problems & $26(81.3)$ & $6(18.8)$ & $0(0.0)$ & $32(68.1)$ \\
\hline & Some Problems & $2(13.3)$ & $13(86.7)$ & $0(0.0)$ & $15(31.9)$ \\
\hline & $\begin{array}{l}\text { Extreme } \\
\text { Problems }\end{array}$ & $0(0.0)$ & $0(0.0)$ & $0(0.0)$ & $\mathbf{0}(\mathbf{0 . 0})$ \\
\hline & Total & $28(59.6)$ & $19(40.4)$ & $\mathbf{0}(\mathbf{0 . 0})$ & $47(100)$ \\
\hline
\end{tabular}


Table 6: Pre vs. Post intervention Scores for EQ-5D for Anxiety/Depression

\begin{tabular}{c|c|ccc|c}
\hline \multirow{2}{*}{\multicolumn{2}{c|}{}} & \multicolumn{3}{|c|}{ Post Intervention n (\%) } & \\
\cline { 3 - 6 } \multicolumn{2}{c|}{} & No Problems & $\begin{array}{c}\text { Some } \\
\text { Problems }\end{array}$ & $\begin{array}{c}\text { Extreme } \\
\text { Problems }\end{array}$ & Total \\
\hline & No Problems & $39(100)$ & $0(0.0)$ & $0(0.0)$ & $\mathbf{3 9}(\mathbf{8 3 . 0})$ \\
\hline & Some Problems & $2(25.0)$ & $6(75.0)$ & $0(0.0)$ & $\mathbf{8}(\mathbf{1 7 . 0})$ \\
\hline & $\begin{array}{c}\text { Extreme } \\
\text { Problems }\end{array}$ & $0(0.0)$ & $0(0.0)$ & $0(0.0)$ & $\mathbf{0}(\mathbf{0 . 0})$ \\
\hline & Total & $\mathbf{4 1 ( 8 7 . 2 )}$ & $\mathbf{6 ( 1 2 . 8 )}$ & $\mathbf{0 ( 0 . 0 )}$ & $\mathbf{4 7}(\mathbf{1 0 0})$ \\
\hline
\end{tabular}

